\title{
Thinking Styles: A Theoretical Account
}

\author{
${ }^{1}$ Hiba M. Abdulkhaliq, ${ }^{2}$ Ansam A. Ismaeel Al-Halawachy \\ 1,2Department of English, College of Basic Education, University of Mosul, Iraq
}

\begin{abstract}
"Thinking styles" is considered as a dynamic construct influenced by diverse biological, psychological, and social factors. The present study aims at introducing some aspects that are related to thinking styles in order to enrich knowledge in this regard. This may be achieved through the theoretical presentation of some topics, through which the researchers hope to serve thinking styles by their brief search, after choosing; according to their view, the most valuable and effective topics that may contribute positively to the educational process.
\end{abstract}

Keywords: thinking styles, teaching styles, academic achievement.

\section{Introduction}

This work is primarily concerned with thinking styles and the direction of the study makes it inevitable to specify the space for discussing some basic issues that are generally related to the subject of thinking styles and its relation to the educational process.

Following this direction, we will tackle thinking styles in general by displaying a brief summary of its conceptualization and origin. Then some definitions of this term is are be dealt with. After that, we will discuss the main principles of thinking styles. Then, in the subsequent sections, a discussion of the main classifications of thinking styles is to be presented. Moreover, this study outlines the role of thinking styles in teaching and learning, along with the effect of thinking styles on academic achievement.

\section{Thinking Styles: Conceptualization and Origin}

This section will succinctly tackle the development of cognitive styles, to make it clear how thinking styles have been appeared independently.

Academic Journal of Nawroz University

(AJNU) Volume 8, No 4 (2019).

Regular research paper : Published 26 Dec 2019

Corresponding author's e-mail : mashallal44@gmail.com Copyright (C2018 Hiba M. Abdulkhaliq, ${ }^{2}$ Ansam A. Ismaeel AlHalawachy. This is an open access article distributed under the Creative Commons Attribution License.
The distant origins of thinking styles go back along with the roots of cognitive styles since the two are being considered joint and closely related to each other. Some researchers, like Hudson (1966), and Jones (2006) consider cognitive styles and thinking styles to be the same. They further argue that a thinking style is one element of cognitive style.

Although the concept of thinking styles is relatively new, it has been introduced into a categorical system of psychological science, especially through very valued theories which have a fundamental contribution in the field of thinking styles especially through the works of Harrison and Bramson (1984), Herrmann (1995), and Sternberg (2002).

If one tries to reduce the diversity of approaches, concepts and theories concerning the stylistic originality of thinking to some common grounds, then, in our opinion, one can identify three main directions. The first direction is a cognitive one that centers around the issue of preferences for certain representational system or the characteristics of the world image, representing the specifics of thinking styles. In this case, thinking is viewed through the originality of the psychological mechanisms involved in the processes of concept formation, information reflection (Berulava, 
2001), or involved in the solution of cognitive tasks (Harrison and Bramson, 1984; Kholodnaya 2004: 384).

The second direction which is functional in nature is associated with the theories and concepts that directly or indirectly lead to the originality of representation of the various functions in thinking that develop thinking styles. The profile of the combination of various selfmanagement functions, in which the thinking of a person is carried out, defines the various thinking styles (Sternberg, 2002).

The third psychophysiological direction explores the psychophysiological basis of person's thinking originality. It seems to us that this direction acts as a key one, because, there is certainly a physiological conditioning of person's thinking originality. Person's thinking differs in its psychophysiological basis, and this is manifested in the specificity of the originality of person's thinking activity (Herrmann, 1995, Bawaneh et al., 2011).

Finally, at the present time, thinking styles including the existence of the theories supporting this field, are considered a very important subject to be investigated, since this will help us reach better understanding of students' thinking styles. Moreover, after making the real concord between them and those of teachers, this will improve the educational process and raise it to the desired level.

\section{Definitions of Thinking Styles}

This section is geared towards discussing researchers' various viewpoints of thinking styles and explaining what they mean by this term.

Various definitions of thinking styles have been introduced by different scholars. The beginning is when "thinking styles" has been considered a kind of intelligence styles which was introduced in 1980 by Harrison and Bramson who define this term by stating that, "thinking styles is not a mental process but a way or method of thinking chosen by individuals for their ability or aptitude to deal with problems, tasks, and situations" (Harrison and Bramson, 1988: 33). Another definition was that of Grigorenko and Sternberg (1995: 220) who treat thinking styles as "a preferred way of expressing or using one or more abilities". They proposed a model of mental selfgovernment for identifying thinking styles and how intelligence is primarily directed to understanding preference, rather than abilities. For Zhang \& Sternberg (2002: 3-12), thinking styles refer to "the way an individual prefers to process and manage the intellect and knowledge".

Another attempt towards a definition of thinking styles was that of Kim (2011:48) who views thinking styles as "the preference for representation and processing of information in the mind, bound to the constituent structure of personality, the consistent way of interacting with the environment, and adapting new information".

\section{Principles of Thinking Styles}

As an extension of what has been introduced so far and regarding the principles of thinking styles, one must pay attention to those basic principles developed by Sternberg (1997: 79-98), and as follows:

- Styles are preferences in the use of abilities, not abilities them-selves. 2. A match between styles and abilities creates a synergy that is more than the sum of its parts.

- Life choices need to fit styles as well as abilities.

- People have profiles (or patterns) of styles, not just a single style.

- Styles are variable across tasks and situations. Styles vary not only with tasks, but with situations.

- People differ in the strength of their preferences.

- People differ in their stylistic flexibility.

- Styles are socialized. 
- Styles can vary across the life span.

- Styles are measurable.

- Styles are teachable.

- Styles valued at one time may not be valued at another.

- Styles valued at one place may not be valued in another

- Styles are not an average, good or bad, it's a question of fit.

- We confuse stylistic fit with levels of abilities.

\section{Classification of Thinking Styles}

It is clearly important to have a complete knowledge about the various views of classification, because of their important role in understanding students' thinking styles and especially in relation to the learning/teaching process. In what follows, we are going to tackle some of the main classifications of thinking styles:

\subsection{Guilford's Classification (1950)}

The term convergent-divergent thinking was known in the early 1950's when Joy Paul Guilford introduced his word of intellect. He describes convergent thinking as "the type of thinking that focuses on coming up with the single, well-established answer to a problem" (As cited in Singh, 2008: 2). The following are the divisions of Guilford's classification.

a. Convergent Thinking Style: is generated toward deriving the most correct answer to a question. It emphasizes speed, accuracy, and logic and focuses on recognizing the familiar, reapplying techniques, and accumulating stored information.

b. Divergent Thinking Style : typically occurs in a spontaneous, free-flowing manner, where many creative ideas are generated and evaluated. Many possible solutions are explored in a short amount of time, and unexpected connections are drawn.

5.2 Das et al.'s Classification(1975)
This classification states that information is integrated in the brain in two ways, either simultaneous or successive processing, and as follows:

- Simultaneous Thinking Style: in this style of thinking each piece of information is immediately accessible in relation to another.

- Successive Thinking Style: It involves the processing of information in a time dependent sequential mode, involving the integration of separate elements into groups whose essential nature is temporal.

\subsection{Torrance et al.'s Classification (1978)}

Torrance et al. (1978: 1) have established their model on the specialized functioning on the cerebral hemispheres. Depending on traditional accounts they assume that thinking styles can be divided as follows:

- The left cerebral hemisphere is the locus of logical, analytical and linear prepositional thought. That is, the left hemisphere seems to process information sequentially and logically.

- In contrast, the right cerebral hemisphere is the center of Visio spatial and oppositional thought and imagination. The right hemisphere seems to process information non-linearly, simultaneously handling a variety of kinds of information.

\subsection{Kirton's Classification (1980)}

Adaptation and innovation are the two dimensions specified by Kirton (1980) for problem solving. Below is a kind of clarification of these types of styles:

a. Adaptation Thinking style: tends to be dogmatic and shows a proliferation of ideas within a framework of rules which preserve the norms. It seeks solutions to problems in tried and understood ways, they are seen as resourceful, efficient, thorough, methodical, organized, precise and reliable.

b. Innovation Thinking Style: innovators tend to 
produce many ideas in problem solving, sacrificing short-term efficiency for longer-term benefits and challenge current structures. They discover problems and avenues for their solutions, they are seen as ingenious, original, energetic, independent, unconventional, insightful and unique.

Kirton (1984a \& 1987 b) identifies the Kirton Adaptation-Innovation Inventory, namely (KAI) as an instrument designed to assess the different ways in which individuals approach problems or their style of problem solving. The inventory has 32 items and one blind item. There are three subscales in it:

1. Originality (creativity),

2. Efficiency (precise, reliable, disciplined), and

3. Rule-Group Conformity (has the proper respect for authority and rules).

\subsection{Harrison and Bramson's Classification (1982)}

Harrison and Bramson identify five preferred thinking styles, viz. synthesists, idealists, analysts, realists and pragmatists. In what follows a simple view of their classification will be presented.

- Synthesis Thinking Style: focuses upon essential factors, underlying assumptions, an abstract, conceptual aspect.

- Idealist Thinking Style: idealists focus on process, relationships, values and aspirations.

- Analytic Thinking Style: analysists are interested in method and plan, they seek predictability through ordinary data and focus on concrete detail.

- Realist Thinking Style: realists focus upon immediately apprehended facts and point to realists and resources.

- Pragmatic Thinking Style: pragmatists focus upon incremental, step-by-step thinking and immediate pay off and tactics.

\subsection{Sternberg's Classification (1988)}

Using government as a metaphor, Sternberg(1988) has proposed that just as there are many ways of governing a society, people have many different ways of managing or governing their activities, and they do so in a style with which they feel comfortable. The following is an overview of mental self-government theory of thinking styles which includes thirteen styles of thinking that have been stipulated in this theory and established on functions, forms, levels and leanings.

\subsubsection{Functions Based Styles}

There are three styles of government:

- Legislative Thinking Style: In the educational institutions, students are about to create, discover, design and do things using their own methods, the stricter is not provided.

- Executive Thinking Style: Students are aware to follow instructions, do what is requested while the structure is provided.

- Judicial Thinking Style: The judicial students prefer activities such as writing critiques, giving opinions, judging others and their work and evaluating programs.

\subsubsection{Forms Based Styles}

Depending on forms, there are four thinking styles, they result in a different way of approaching the world and its problems. They are as follows:

- Monarchic Thinking Style: Educationally, a student tends to do one thing at a time, spends almost all the energy and resources on it.

- Hierarchic Thinking Style: A hierarchic student likes to do many things at once, prioritizes what and when to do a thing and how much time and energy to spend on it.

- Oligarchic Thinking Style: Students can do many things at once, but facing troubles in prioritizing. 
- Anarchic Thinking Style: A student likes to follow an extraordinary approach to solve problems, hates systems, guidelines and directions.

\subsubsection{Levels Based Styles}

Two thinking styles are based on levels. They are as follows:

- Global Thinking Style: A Student with this style likes to work with the bigger picture, generalizations and abstracts .

- Local Thinking Style: A student in local style likes to work with details, specifications and concrete examples.

\subsubsection{Scope Based Styles}

Based on scope of mental self-government, two styles of thinking have been identified. They are:

- Internal Thinking Style: Students like to work alone, focus on the inside and are independent.

- External Thinking Style: Students like to work with others whenever possible, focus on the outside and are interdependent.

\subsubsection{Leanings Based Styles}

Based on leaning of mental self-government, two styles of thinking have been identified:

- Liberal Thinking Style : The student with liberal style likes to go beyond existing rules and procedures, to maximize change and to seek situations that are somewhat ambiguous. That is, to do things in a new manner and deviates from traditions.

- Conservative Thinking Style : A student tends to do things in a proven and real manner and follows traditions. The following figure demonstrates thinking styles classification:

\subsection{Basadur et al.'s Classification (1990)}

The research done by Basadur et al. has produced the concept that a unique personal style of creative problem solving can be characterized for each individual. Basadur et al. have provided two major dimensions of the process of problem solving. The first dimension (Experiencing vs. Thinking). The second dimension, (Ideation vs. Evaluation). The main classification of Basadur et al. is as follows:

- Generative Thinking Style: The quadrant I orientation toward creative problem solving is called generator.

- Conceptual Thinking Style: the quadrant II orientation is called conceptualizer.

- Optimization Thinking Style: the quadrant III orientation toward creative problem solving is called optimizer.

- Implementive Thinking Style: the quadrant IV orientation is called implementer.

\subsection{Epstein et al.'s Classification (1996)}

Epstein et al. have identified two modes of thinking styles. They are popularly known as intuitiveexperimental and analytical-rational thinking styles. This is based on cognitive-experimental self-theory of personality. The following is an explanation of Epstein et al.'s classification:

- Experimental Thinking Style: Epstein et al. (1996) claim that we are held back by our emotions and self obviously, experiencing is believing.

- Rational Thinking Style: We are in active conscious awareness of our control over our ideas which requires also justification across logic and evidence(ibid.).

\section{The Role of Thinking Styles in Teaching and Learning} It has been well documented in educational literature that effective learning occurs if the whole brain participates in learning.

Cognitive functions are absorbed when educational activities are generated to comply with the learner's 
preferred way of thinking. This is explained in terms of the Herrmann's Brain Model (1995), which assumes that

all four quadrants in the brain are included in teaching and learning activities. This model also helps to understand the mental diversity and important role it plays in effective teaching and learning, as well as being a tool for designing and delivering teaching and learning work across all four quadrants ( De Boer and Steyn,1999: 97).

This model helps to understand mental diversity and the important role of not only effective teaching and learning, but also a tool for designing and delivering teaching and learning activities in all four quarters of the brain. The Herrmann Four Quadrant Whole Brain Model is the only tool that determines a person's preference for thinking in four different situations based on the specialized function of the brain (Herrmann 1995:72).

As a result, cognitive functions are realized when instructional activities are created to conform to the learner's preferred thinking/ learning method and are best used when learning activities are created in such a way that cognitive functions are connected to all four quarters of the Herrmann model. In other words, the researchers agree with other scholars, namely Knowles(1990), Buzan(1991), Jensen(1996) and Ornstein(1997) that

effective learning takes place if the whole brain is involved in learning. Interpreted in terms of Herrmann's model this presupposes that all four quadrants are included in teaching and learning activities.

\section{Thinking Styles and Academic Achievement}

Many factors including cognitive ability, personality traits and family play a major role in students' academic achievement" (Pashaei et al., 2009, cited in Fatemi and Heidari, 2016:1354). In fact, academic achievement is one of the most important factors in educational environments, especially in schools. As active human beings, students play a key role in the development of societies, with rich and rich countries having effective human capacities today.

Educators seek to provide conditions for learners to achieve the highest academic achievement. The identification of variables that affect achievement and control learners is one of the most important goals of the educational systems in the world in order to increase learners' educational achievement. Therefore, "since learning is the primary goal of education, and since it is measured mainly in terms of academic achievement of learners, determining factors affecting it is important" (Motlagh et al., 2014: 82).

Academic achievement means the ability of students to solve the problems of pre-defined curriculum content (Sepahvandi, 2000: 141-150). In addition, academic achievement includes the recording of all cognitive activities of learners measured through a common registration system in relation to the different levels of emotional and educational activities and the schedule, and is considered as a process of academic achievement (Khoshkonesh, 2007, cited in, Fatemi and Heidari, 2016:1354).

Sternberg and Grigorenko(1993) and Grigorenko and Sternberg (1997) have shown that there is a positive role of thinking styles in academic achievement. Moreover, Bernardo et al. (2002) have investigated the relationship between students' academic thinking and achievement in the Philippines and have concluded that executive 
and judicial thinking styles is positively related to academic achievement. Other investigations have been made by Zhang (2001) and Casidy (2013: 841-856) which have showed that "conservative thinking style positively predicts academic achievement, and that general thinking style and liberal thinking style predicts it negatively".

It is obvious that although not all thinking styles are positively related to academic achievement, but the ones that do are playing a crucial role in developing students' awareness and contribution to their academic achievement through predictions.

\section{Conclusions and Implications for Teaching}

The conclusions of any research are conducted from what already has been discussed in the previous sections of the research. The researcher have concluded that thinking styles can be treated as a predicative component within the field of teaching and learning which may contribute a lot to the educational outcomes.

Additionally, the educational process is on real update frequently, and teachers and learners are the ones who create this developmental movement in teaching and learning realms through the consistency in their thinking styles.

In the light of the aforementioned conclusions, some implications for teaching may be derived dependently, as such, new courses of more modern and developed teaching styles through which teachers could be familiar with thinking styles may the researchers advise to be designed and studied by specialists to thorough the educational process along with the point that, the role of thinking styles is seen to be effective and have good contribution to students learning process, if properly adopted and supported with qualified requirements.
Finally, the researchers find that, better outcomes can be observed if concord between thinking styles of teachers and students, is conducted. That is, the more the teacher is familiar with his/her students' thinking styles and the more knowledgeable the teacher is, the more the teaching results will be satisfied.

\section{References}

1. Basadur, M., Wakabayashi, M. \& Graen, G. B. (1990). "Individual Problem-Solving Styles and Attitudes towards Divergent Thinking Before and After Training" . Creativity Research Journal, vol. 3, pp. 22-32.

2. Bawaneh, A. , Abdullah, A. , Saleh, S., \& Yin, K. (2011). “Jordanian students' thinking styles based on Herrmann whole brain model". International Journal of Humanities and Social Science, vol.1(9), pp.89-97. Retrieved: 20.08.2013. Special Issue, July, 2011/12. pdf. [Online] available: http://www.ijhssnet.com/journals-

3. Bernardo, A.B., Zhang, L.F. \& Callueng, C.M. (2002). "Thinking Styles and Academic Achievement among Filipino Students". The Journal of Genetic Psychology, vol. 163(2), pp. 149-163.

4. Berulava, G. A. (2001). Style of Individuality: Theory and Practice. M.: Amyls.

5. Buzan, T. (1991). Use Both Sides of Your Brain. New York, Plume.

6. Casidy, H. (2013). “Relationship between Thinking Styles Inventory and Study Process Questionnaire?" Personality and Individual Difference, vol. 29, pp. 841856.

7. Das, J. P., Kirby, J. P. \& Jarman, P. F. (1975). Simultaneous and Successive Synthesis: An Alternative Model for Cognitive Abilities. Psychological Bulletin, vol. 82, pp. 87-103.

8. De Boer, A. \& Steyn, T. 1999. “Thinking Style Preferences of Underprepared First Year Students in the Natural Sciences" . South African Journal of Ethnology, vol. 22 (3), pp. 97-102.

9. Epstein, S., Pacini, R., Denes, V. \& Heier, H. (1996). "Individual Differences in Intuitive-Experiential and Analytical Rational Thinking Styles". Journal of 
Personality and Social Psychology, vol. 17 (2), pp. 390 405.

10. Fatemi, M. \& Heidari, A. (2016). “Relationship between Thinking Styles and Academic Achievement of the Students". International Journal of Humanities and Cultural Studies, vol. 2(4), pp. 1358- 1361.

11. Grigorenko, E. L., \& Sternberg, R. J. (1995). “Thinking Styles" . In Saklofske. D. \& Zeidner. M.(Eds.), International Handbook of Personality and Intelligence, New York: Plenum.

12. (1997). Styles of Thinking, Abilities and Academic Performance. Exceptional Children, vol. 63(3), pp. 295312.

13. Guilford, J. P. (1950). "Creativity" American Psychologist, vol. 5, pp. 444-454.

14. Harrison, A. F. \& Bramson, R. M. (1982). Styles of Thinking. New York, Double Day.

15. (1984). The Art of Thinking: Strategies for Asking Questions, Making Decisions, and Solving Problems. Berkley.

16. (1988). An Introduction to Thinking Styles. [Online]. USA, Berkley Publishing Group, and Be Jo Sales Incorp. Retrived June 14,2009, from [Online] available www.earthtym.net/s-

17. Herrmann, N. (1995). The creative brain. (2nd Ed.). Kingsport: Quebecor Printing Book Group.

18. Hudson, R. (1996). Sociolinguistics . Cambridge University Press, London.

19. Jensen, E. (1996). Brain-Based Learning. Turning Point Publishing. Del Mar, Ca, USA.

20. Jones, M. (2006). Thinking style differences of female college and university presidents. A National Study. Marshall University, Huntington, West Virginia.

21. Kholodnaya, M. A. (2004). Cognitive Styles. On the Nature of the Individual Mind, 2nd Eds. Piter, St. Petersburg. Russia.

22. Kim, M. (2011). “The Relationship Between Thinking Style Differences and Career Choice for High Achieving Students" . Journal of Roeper Review, vol. 33(4), pp.48.

23. Kirton, M. J. (1980). "Adaptors and Innovators in Organizations". Human Relations, vol. 33, pp. 213-224.
24. (1984a). "Personality Characteristics Associated with Adaption-Innovation" The Jornal of Psychology, vol. 117(2), pp. 159-165. [Online] available: https://doi.org/10.1080/00223980.1984.9923672-.

25. (1987b). Kirton adaption-innovation inventory manual. Hatfield, England: Occupational Research Centre.

26. Knowles, M. (1990). The Adult Learner -A Neglected Species (4th edition). USA, Gulf Publishing Company.

27. Motlagh, F., Jalilian, F., Mari, A., Mahboby, M., Aghaei, A., Merzaei, M. (2014). “Explain of Ecstasy Use among Kermanshah Adolescents, The West of Iran : An Application of the theory of Planned Behavior". Life Sci J. vol, 11(1), pp.82.

28. Ornstein, R. (1997). The Right Mind: Making Sense of the Hemispheres. New York, Harcourt Brace \& Company.

29. Sepahvandi, M. A. (2000). "A Study on Emotional, Familial, Behavioral and Personality Characteristics of University Student Clients Visiting the Lorestan University Counseling Center". Journal of Education and Psychology, vol. 3, (1-2), pp. 141-150.

30. Sternberg, R. J. (1988). "Mental Self-Government: A Theory of Intellectual Styles and Their Development". Human Development, vol. 31, pp.197-224.

31. (1997). Thinking styles. Cambridge: Cambridge University Press.

32. (2002). Thinking Styles. Reprinted Edition, UK, Cambridge University Press.

33. Sternberg, R.J., \& Grigorenko, E.L. (1993). Thinking styles and the gifted. Roeper Review, vol.16(2), pp. 122-130.

34. https://doi.org/10.1080/02783199309553555- .

35. Torrance, P. \& Moured, S. (1978). “Some Creativity and Style of Learning and Thinking Correlates of Gugliemmos Sell Directed Learning Readiness Scale". Psychological Reports, vol. 43, pp. 1167-1171.

36. Zhang, L. F. (2001). "Relationship between Thinking Styles Inventory and Study Process Questionnaire?" Personality and Individual Difference, vol. 29, pp. 841856.

37. Zhang, L. F., \& Sternberg, R. J. (2002). “Thinking Styles and Teachers' Characteristics" . International Journal of Psychology, vol.37(1), pp.3-12. 